\title{
Radial Nanowire Light-Emitting Diodes in the (AlxGa1-x)yIn1-yP Material System
}

Berg, Alexander; Yazdi, Sadegh; Nowzari, Ali; Storm, Kristian; Jain, Vishal; Vainorius, Neimantas; Samuelson, Lars ; Wagner, Jakob Birkedal; Borgström, Magnus T

\section{Published in:}

Nano Letters

Link to article, DOI:

10.1021/acs.nanolett.5b04401

Publication date:

2016

Document Version

Peer reviewed version

Link back to DTU Orbit

Citation (APA):

Berg, A., Yazdi, S., Nowzari, A., Storm, K., Jain, V., Vainorius, N., Samuelson, L., Wagner, J. B., \& Borgström, M. T. (2016). Radial Nanowire Light-Emitting Diodes in the (Al $\left.\mathrm{Ga}_{1-\mathrm{x}}\right) \mathrm{yln} \mathrm{n}_{1-\mathrm{y}} \mathrm{P}$ Material System. Nano Letters, 16(1), 656-62. https://doi.org/10.1021/acs.nanolett.5b04401

\section{General rights}

Copyright and moral rights for the publications made accessible in the public portal are retained by the authors and/or other copyright owners and it is a condition of accessing publications that users recognise and abide by the legal requirements associated with these rights.

- Users may download and print one copy of any publication from the public portal for the purpose of private study or research.

- You may not further distribute the material or use it for any profit-making activity or commercial gain

- You may freely distribute the URL identifying the publication in the public portal 


\section{Radial nanowire light-emitting diodes in the} Sweden †Center for Electron Nanoscopy, Technical University of Denmark, DK 2800 Kgs. ${ }^{\S}$ Laboratory of Mathematics, Physics and Electrical Engineering, Halmstad University, Box 823, SE-301 18 Halmstad, Sweden

13 Keywords: Nanowire, radial, quantum well, STEM-EDX, light-emitting diodes, MOCVD Nanowires have the potential to play an important role for next-generation lightemitting diodes. In this work we present a growth scheme for radial nanowire quantumwell structures in the AlGaInP material system using a GaInP nanowire core as a template for radial growth with GaInP as the active layer for emission and AlGaInP as charge carrier barriers. The different layers were analyzed by x-ray diffraction to ensure 
21 lattice-matched radial structures. Furthermore we evaluated the material composition and hetero-junction interface sharpness by scanning transmission electron microscopy energy dispersive x-ray spectroscopy. The electro-optical properties were investigated by injection luminescence measurements. The presented results can be a valuable track towards radial nanowire light-emitting diodes in the AlGaInP material system in the red/orange/yellow color spectrum.

Nanowires (NWs) are future building blocks for optoelectronic devices such as solar cells, ${ }^{1}$ transistors ${ }^{2}$ and light-emitting diodes. ${ }^{3}$ Due to the small dimensions, NWs can exhibit different electronic and optical properties as compared to planar structures of the same materials. Material combinations that are incompatible in planar structures can be used in NWs, allowing more freedom in bandgap tuning of active segments to desired wavelengths in NW based devices.

It is a common practice in III-As/P planar light-emitting diode structures to use GaInP as the active layer. ${ }^{4-18}$ By introducing $\mathrm{Al}$ in GaInP, the bandgap can be increased all the way to $2.52 \mathrm{eV}$ in $\mathrm{AlP}$, but which has an indirect bandgap. ${ }^{19}$ The Al/Ga ratio in lattice-matched AlGaInP can be tuned to be used as electron blocking layer keeping the $(\mathrm{AlGa}) / \mathrm{In}$ ratio constant since the lattice constant changes only slightly with increasing Al due to similar lattice constants for AlP and GaP. ${ }^{19},{ }^{20}$ In planar structures, LEDs based on the AlGaInP material system are often grown on GaAs substrates, since $\left(\mathrm{Al}_{\mathrm{x}} \mathrm{Ga}_{1-\mathrm{x}}\right)_{0.51} \mathrm{In}_{0.49} \mathrm{P}$ is lattice-matched to GaAs. ${ }^{19}$ After synthesis, the GaAs substrate is replaced by a transparent GaP substrate via "wafer-bonding". ${ }^{21-24}$ Alternatively, in order to grow $\mathrm{Ga}_{0.47} \mathrm{In}_{0.53} \mathrm{P}$ which leads to red light emission ${ }^{25}$ on $\mathrm{GaP}$, graded buffer layers are needed to adjust for the $3.6 \%$ lattice mismatch. ${ }^{19,}{ }^{20}$ Graded buffer layers usually 
exhibit dislocations which lead to efficiency losses. Therefore the possibility to achieve desired bandgaps is limited. In the NW geometry, the desired composition can be grown

47 directly on substrates with different lattice constants because of the small NW footprint $^{26,27}$ and due to effective strain relaxation via the free surfaces in NWs. For designing radial NW structures lattice matching requirements become more relevant, and the NW core can be used as a "substrate" for growing NW shells that are latticematched with the NW core. Radial core-shell NWs have been shown to be a versatile structure for light-emitting diodes ${ }^{28,29}$ because of the larger junction area as compared to axial NW structures. Several contributions on radial NW quantum-well (QW) structures with emission in the infrared (IR) color spectrum based on various material systems have been reported such as $\mathrm{GaP} / \mathrm{GaAs} / \mathrm{GaInP},{ }^{30} \mathrm{InP} / \mathrm{InAsP} / \mathrm{InP},{ }^{31}, \quad 32$ InP/InAs/InP ${ }^{33}, 34$ and GaAs/AlGaAs. ${ }^{35-38}$ Moreover, radial NW QWs in the shortwavelength visible spectrum with $\mathrm{GaN} / \mathrm{InGaN} / \mathrm{GaN}^{28,} 29,39$ as well as multi-quantumwell (MQW) structures in (In)AlN/GaN ${ }^{40,41}$ emitting in the ultra-violet (UV) region have been reported. Here, we report the growth and characterization of radial NW p-i-n

60 junctions in the AlGaInP material system designed for the long-wavelength visible spectrum. We grow untapered GaInP NW cores on a GaP substrate and use the NW core as a template for radial growth of materials with composition optimized for red light emission. After growing a radial QW structure, the material composition is 64 analyzed, and the effect of different n-type dopant precursors on the growth dynamics is studied. We observe Al enrichment in the corners of the AlGaInP layers in the cross-

66 section perpendicular to the NW axis by use of transmision electron microscopy (TEM).

67 Electrical measurements confirm the presence of a pn-junction and electrical injection results in luminescence in the red color spectrum. 
P-doped $(\overline{1} \overline{1} \overline{1}) \mathrm{B}$ GaP wafers were deposited with a $20 \mathrm{~nm}$ thick silicon nitride

$70 \quad\left(\mathrm{SiN}_{\mathrm{x}}\right)$ layer via plasma-enhanced chemical vapor deposition (PECVD). Resist-spinning 71 with a bi-layer method, ${ }^{42}$ nanoimprint lithography (IPS/STU process ${ }^{43}$ ), reactive ion 72 etching (RIE), Au evaporation and lift-off were used to define the template for NW 73 growth. The template consists of a hexagonal pattern of circular holes of $100 \mathrm{~nm}$ with a 74 pitch of $1 \mu \mathrm{m}$. The deposited Au layer thickness was $10 \mathrm{~nm}$. The material design of the p-type GaInP NW core was reported elsewhere. ${ }^{44}$ In short, the core consists of a GaP stub, a GaInP transition segment where the Ga content decreases from $\mathrm{p}-\mathrm{GaP}$ to $\mathrm{p}$ GaInP of the composition intended for the NW and a long p-GaInP segment with homogenous material composition. The complete radial structure is formed by depositing several additional shell layers on the core: a p-GaInP buffer layer (15 s growth time), a p-AlGaInP cladding layer (30 s), an intrinsic GaInP layer (15 s) as the active layer for carrier recombination, an n-AlGaInP cladding layer (30 s) and an nGaInP layer (2 min) which is intended to be highly doped for electrical contacts (Figure 1). The p-GaP wafer below the shells is passivated by the $\mathrm{SiN}_{\mathrm{x}}$ mask in order to make more precursor material contribute to NW growth and avoid substrate leakage currents from the outermost shell directly into the substrate in device configuration. The NWs were grown by metal-organic chemical vapor deposition (MOCVD) in an Aixtron 200/4 reactor at a pressure of 100 mbar for the core and 50 mbar for the shells. The precursors were trimethylaluminum (TMAl), trimethylgallium (TMG), trimethylindium (TMI), 89 phosphine $\left(\mathrm{PH}_{3}\right)$ as well as diethyl zinc (DEZn) for p-type doping and triethyltin (TESn) or hydrogen sulfide $\left(\mathrm{H}_{2} \mathrm{~S}\right)$ for n-type doping, respectively, in a total flow of $13 \mathrm{l} / \mathrm{min}$ using hydrogen $\left(\mathrm{H}_{2}\right)$ as carrier gas. Hydrogen chloride $(\mathrm{HCl})$ was used to impede radial growth during the synthesis of the NW core. ${ }^{45-48}$ The molar fractions for growth of the 
$93 \mathrm{p}$-GaInP segment of the core at $440{ }^{\circ} \mathrm{C}$ were $\chi_{\mathrm{TMG}}=6.724 \times 10^{-5}, \chi_{\mathrm{TMI}}=1.228 \times 10^{-5}, \chi_{\mathrm{PH} 3}$

$94=4.6 \times 10^{-3}, \chi_{\mathrm{DEZn}}=3.13 \times 10^{-6}$ and $\chi_{\mathrm{HCl}}=6.154 \times 10^{-5}$. After growth of the NW core with

95 a length of $1.5 \mu \mathrm{m}$ and cooling the reactor under a $\mathrm{PH}_{3} / \mathrm{H}_{2}$ mixture, the sample was 96 taken out of the reactor and the gold alloy particle removed by a two-step wet chemical

97 etch process in order to impede catalyzed axial growth during shell growth using $98 \mathrm{H}_{2} \mathrm{SO}_{4}: \mathrm{H}_{2} \mathrm{O}(1: 10)$ and $\mathrm{KI}: \mathrm{I}_{2}: \mathrm{H}_{2} \mathrm{O}(4 \mathrm{~g}: 1 \mathrm{~g}: 40 \mathrm{ml}){ }^{49-51}$ both for $10 \mathrm{~s}$. After loading the 99 sample back into the reactor, it was heated to $650{ }^{\circ} \mathrm{C}$ and the sample was annealed for 4 100 min under a $\mathrm{PH}_{3} / \mathrm{H}_{2}$ mixture to remove any oxides on the $\mathrm{NW}$ core surface. The shell 101 growth of the different layers, at $650{ }^{\circ} \mathrm{C}$, was initialized/terminated by switching on/off 102 the respective group III and dopant precursor sources. The molar fractions of TMI, $\mathrm{PH}_{3}$ 103 and DEZn during shell growth were $\chi_{\mathrm{TMI}}=3.509 \times 10^{-5}, \chi_{\mathrm{PH} 3}=1.54 \times 10^{-2}$ and $\chi_{\mathrm{DEZn}}=$ $1043.13 \times 10^{-6}$, respectively. For every shell we performed a series of growth experiments on 105 different samples from the same NW core growth run with varying $\chi_{\mathrm{TMG}}$ for the GaInP 106 shells and a varying sum $\left(\chi_{\mathrm{TMAl}}+\chi_{\mathrm{TMG}}\right)$ for the AlGaInP shells (but keeping the $\chi_{\mathrm{TMAl}} /$ $107\left(\chi_{\mathrm{TMAl}}+\chi_{\mathrm{TMG}}\right)$ ratio constant $)$, respectively, in order to achieve lattice-matched 108 compositions between all layers. The molar fractions for TMAl, TMG and the n-type 109 dopants for lattice-matched layers are shown in Table S1. Applying growth parameters 110 for lattice-matched layers using $\mathrm{H}_{2} \mathrm{~S}$ as n-type dopant, we performed five growth runs 111 with different $\chi_{\mathrm{TMAl}} /\left(\chi_{\mathrm{TMAl}}+\chi_{\mathrm{TMG}}\right)$ ratios (but with constant $\left.\operatorname{sum}\left(\chi_{\mathrm{TMAl}}+\chi_{\mathrm{TMG}}\right)\right)$

112 (Table S2) to evaluate the correlation between the group III precursor molar fractions in 113 the gas phase and the Al concentration in the AlGaInP crystal (Table S2). After shell 114 growth, the sample was cooled down to room temperature under a $\mathrm{PH}_{3} / \mathrm{H}_{2}$ mixture. 

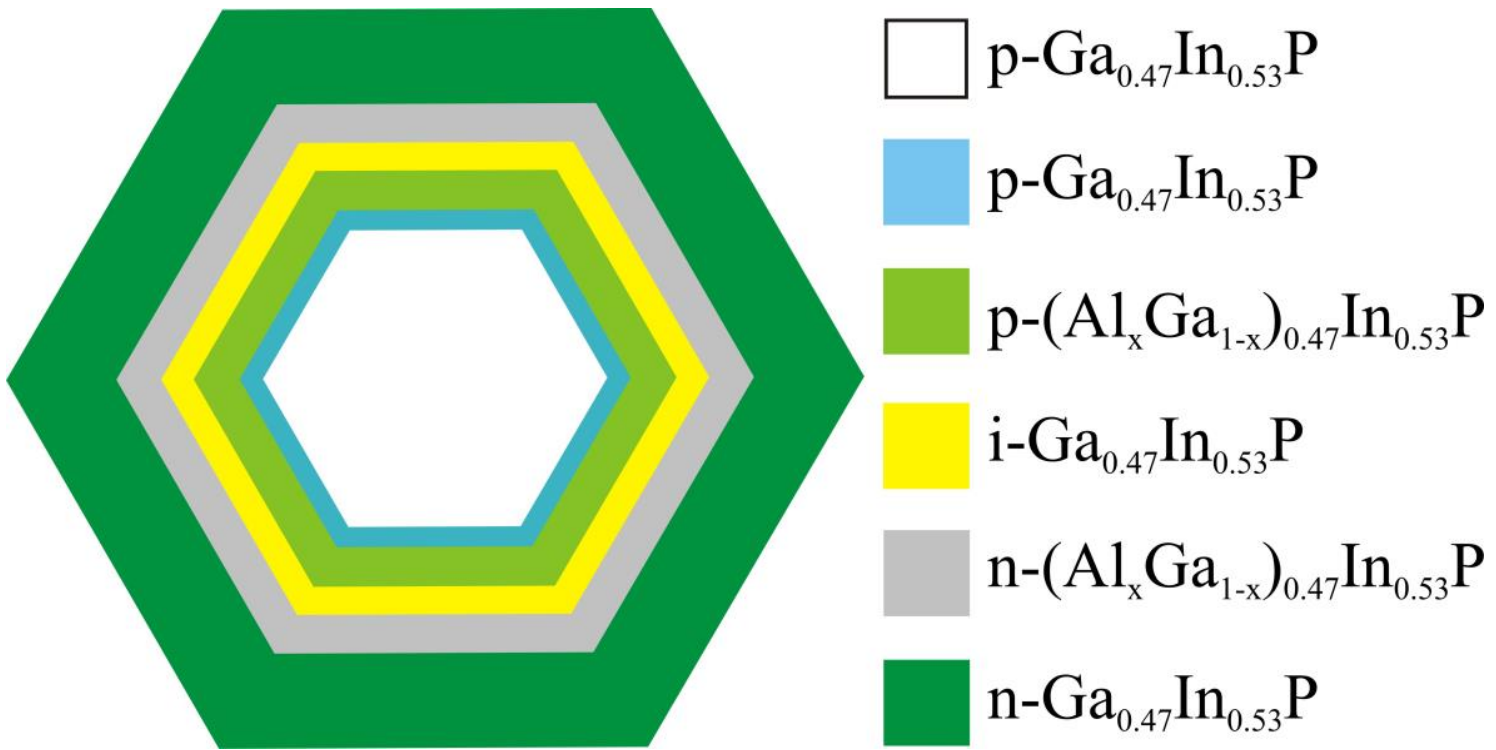

118 Figure 1. Schematic construction of the grown radial GaInP/AlGaInP/GaInP NWs. The

119 different colors indicate the strain-free layers with desired compositions during the

120 development of the radial structure. The white area in the center is the NW core.

Scanning electron microscopy (SEM) was used to characterize the length, diameter and surface morphology of over $30 \mathrm{NWs}$ in the center of each sample.

In order to determine the ratio between $\mathrm{Ga}$ and $\mathrm{In}$ in GaInP shells and between $(\mathrm{Al}+\mathrm{Ga})$ and $\mathrm{In}$ in $\mathrm{AlGaInP}$ shells, respectively, $\mathrm{x}$-ray diffraction (XRD) characterization was used. The measurements reveal the composition range in a large amount of NWs from the probed area of the sample corresponding to a few $\mathrm{mm}^{2}$. Each shell in Figure 1 was characterized individually. After optimization of the p-GaInP shell, the neighboring $\mathrm{p}$-AlGaInP shell was developed according to XRD measurements and so on. Most of these measurements were done during developing a procedure to grow ternary GaInP NW with homogeneous material composition by ramping $\chi_{\mathrm{TMI}}$ up by $25 \%$ during a growth time of $4 \mathrm{~min}^{44}$ Therefore most of the NW cores, except the ones with S-doped n-GaInP shells, had an inhomogeneous composition along the axial 
134 direction of the NW. In order to determine the material composition, the shell under 135 investigation was grown 4-6 times longer than in the final structure in order to get a 136 proper XRD signal from the respective shell which by volume is dominated by the shell 137 under evaluation although it contains the signal from the entire NW (including the broad 138 XRD signal from the NW core). According to Schubert ${ }^{25}$ GaInP has a bandgap between 1391.65 and $1.99 \mathrm{eV}$ in the red color spectrum, which corresponds to an XRD angle 140 between 27 and 27.4 degrees for 2 Theta for a crystal growing in ( $\overline{1} \overline{1} \overline{1}) \mathrm{B}$ direction. For 141 each shell the composition was aimed at $\mathrm{Ga}_{0.47} \mathrm{In}_{0.53} \mathrm{P}$ and $\left(\mathrm{Al}_{\mathrm{x}} \mathrm{Ga}_{1-\mathrm{x}}\right)_{0.47} \mathrm{In}_{0.53} \mathrm{P}$, 142 respectively, which for GaInP corresponds to a bandgap of $1.82 \mathrm{eV}^{25}$ and for the NW 143 core and all shells to an XRD angle 2 Theta of 27.2 degrees.

144 The NWs were studied by TEM analysis in a probe corrected FEI Titan 80-300 145 ATEM. Cross-sectional TEM specimens from five samples grown with different $\chi_{\mathrm{TMAl}} /$ $146\left(\chi_{\mathrm{TMAl}}+\chi_{\mathrm{TMG}}\right)$ ratios in the AlGaInP layers were prepared using focused ion beam 147 (FIB) milling. All the TEM specimens were prepared perpendicular to the axial NW 148 axis of the full core-shell structure (including all layers) in the middle of the axial 149 elongation of the NWs. To study the structure and map the compositional distribution in 150 the NWs, atomic resolution scanning TEM (STEM) and high-angle annular dark-field 151 STEM (HAADF STEM) together with energy dispersive x-ray spectroscopy (EDX) were performed.

153 In order to optimize the structure for injection luminescence (IL) measurements,

154 we further developed the epitaxial structure. The growth time for the upper segment of 155 the p-GaInP NW core was increased to $6 \mathrm{~min}$ to get $1.8-2 \mu \mathrm{m}$ long NWs and consequently the ramping range for $\chi$ TMI increased to about $50 \%,{ }^{44}$ which resulted in a

157 ternary p-type $\mathrm{Ga}_{0.47} \mathrm{In}_{0.53} \mathrm{P} \mathrm{NW}$ core with homogeneous material composition. On top 
158 of the p-GaInP NW core an $\mathrm{n}$-GaP top segment was added in order to avoid leakage

159 from the outermost shell directly into the NW core. The p-GaInP buffer layer

160 (innermost shell) was grown thicker (2 min growth time instead of $15 \mathrm{~s}$ ) to fill any

161 possible gap between the NW core and $\mathrm{SiN}_{\mathrm{x}}$ mask opening and therefore to avoid any

162 current leakage from the QW directly into the substrate. The AlGaInP barriers were

163 grown non-intentionally doped instead of previously $\mathrm{p}$ - and $\mathrm{n}$-doped during the

164 development of lattice-matched NW shells. The highest $\chi_{\mathrm{TMAl}} /\left(\chi_{\mathrm{TMAl}}+\chi_{\mathrm{TMG}}\right)$ ratio of

1650.63 out of five different growth runs (Table S2) was used to have the highest possible

166 AlGaInP barrier height of our series. Thus the carriers are even more effectively trapped

167 in the QW. For the i-GaInP QW, we made a series of three different growth times (15,

16830 and $60 \mathrm{~s}$ ). Preliminary IV-measurements indicated higher rectification ratios using

169 tin (Sn) in the outermost shell as compared to sulphur (S), similar to InP core-shell NW

170 pn-junctions. ${ }^{50,52}$ Therefore we doped the outermost $\mathrm{n}$-GaInP shell with $\mathrm{Sn}$ and

171 increased $\chi_{\text {TESn }}$ to $1.314 \times 10^{-5}$.

172 In order to assess the electrical properties of the NWs, $100 \times 100 \mu \mathrm{m}^{2}$ large test

173 LED devices were fabricated. UV lithography and wet etching were used to define the

174 device area and the transparent electrical contacts to the NW shells were fabricated by

175 sputtering indium-tin-oxide (ITO) on the NWs, whereas the NW cores were electrically

176 contacted via the p-type substrate. ${ }^{52}$

177 A probe station was used for measuring IV curves (Figure 4b) at room

178 temperature, whereas IL measurements (Figure 4d) were carried out in another setup - at

179 room temperature as well - in which the outcoming light was collected and measured by

180 a fiber spectrometer. Special care was taken that the relative position between the 
181 detector and the sample was identical for different samples in order to compare the light 182 intensity.

183 In order to develop a process flow for growing NWs with a radial geometry, it is 184 crucial to design and optimize the growth parameters for each layer in the structure 185 separately. Thereby we analyze the material composition for each layer as a function of 186 group III precursor molar fractions and aim at strain-free NW shells with compositions of $\mathrm{Ga}_{0.47} \mathrm{In}_{0.53} \mathrm{P}$ and $\left(\mathrm{Al}_{\mathrm{x}} \mathrm{Ga}_{1-\mathrm{x}}\right)_{0.47} \mathrm{In}_{0.53} \mathrm{P}$ for GaInP and AlGaInP layers shown in Figure

1. The p-GaInP buffer layer is used for re-nucleation, in order to overcome any potential surface defects with respect to morphology during wet-etching of the gold alloy particle. XRD measurements show that a crystal composition of Ga0.47 $\operatorname{In}_{0.53} \mathrm{P}$ (XRD angle 2

191 Theta $=27.2^{\circ}$ ) can be achieved by tuning $\chi_{\mathrm{TMG}}$ to $3.812 \times 10^{-5}$ (Figure $2 \mathrm{a}$ ). Figure $2 \mathrm{~b}$ 192 shows the composition of the p-GaInP layer as a function of $\chi_{\mathrm{TMG}}$ calculated based on 193 XRD measurements.
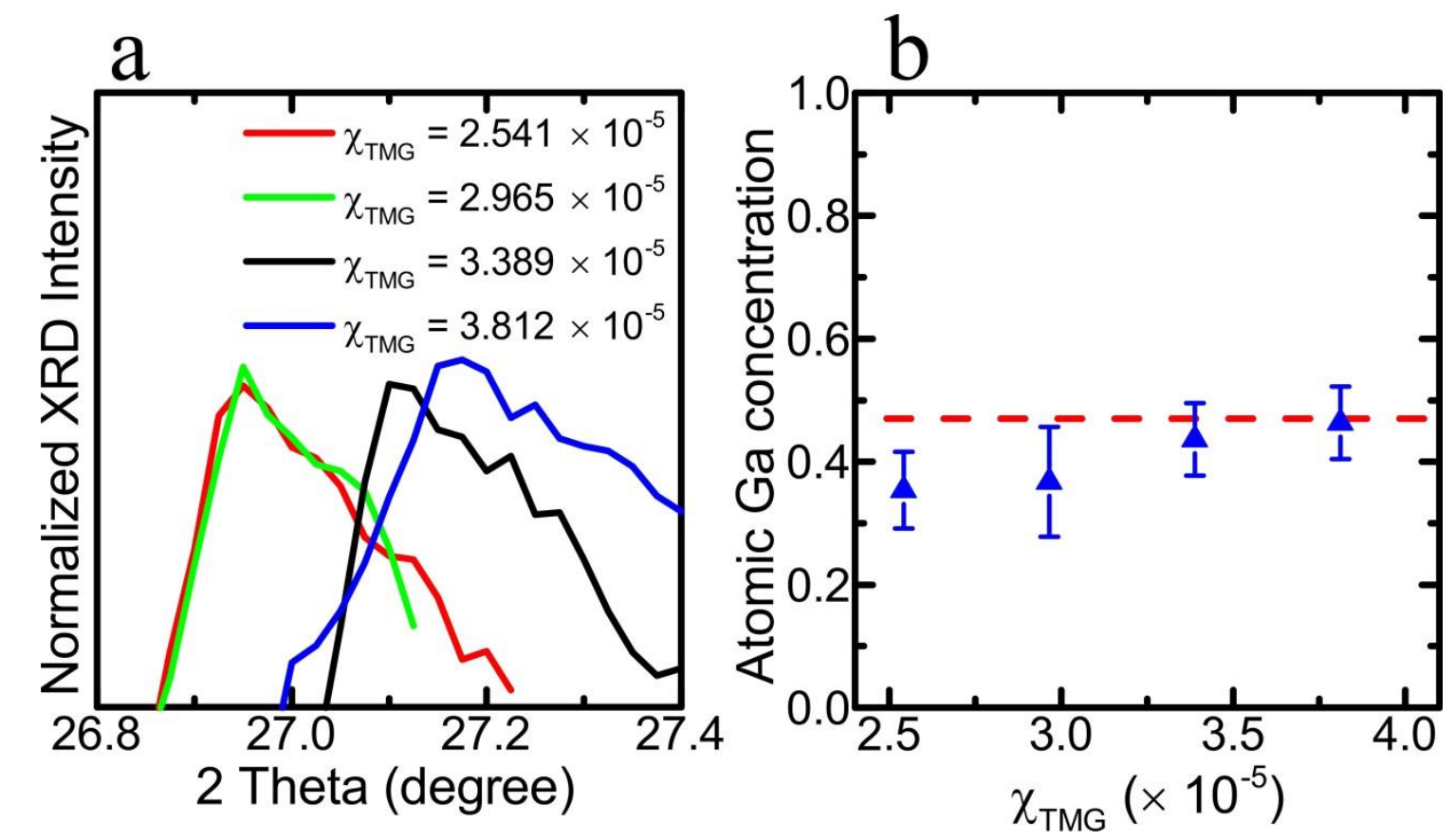

195 Figure 2. (a) XRD graph for the p-GaInP NW shell layer depending on different $\chi_{\text {TMG. }}$ 
197 signal for the two lower molar fractions is cut outside the peak for visibility reasons.

198 The GaP substrate peak is at $28.34^{\circ}$. (b) Atomic Ga concentration for the p-GaInP layer

199 as a function of $\chi_{\mathrm{TMG}}$. The error bars indicate the composition range which was

200 determined with the FWHM. ${ }^{44}$ The dashed line shows the desired composition

$201 \mathrm{Ga}_{0.47} \operatorname{In}_{0.53} \mathrm{P}$ which corresponds to an XRD 2 Theta degree of $27.2^{\circ}$.

202

As stated earlier, most NW cores had an inhomogeneous material composition ${ }^{44}$

204 during the development of lattice-matched shells. Especially for the p-GaInP and p-

205 AlGaInP shell, the composition of the "upper segment" of the core varied from

$206 \mathrm{Ga}_{0.3} \mathrm{In}_{0.7} \mathrm{P}$ to $\mathrm{Ga}_{0.44} \mathrm{In}_{0.56} \mathrm{P}$, which was determined with the full-width-at-half-maximum

207 (FWHM $)^{44}$ of the XRD signal for the NW core. Also for the NW shells we observe a

208 broader XRD signal than what is typically observed for completely homogeneous

209 ternary NW materials, ${ }^{44}$ which indicates that the NW shell growth also results in an

210 inhomogeneous composition along the axial direction of the NW shell. The growing

211 layer tends to adopt the lattice spacing of the underlying layer and the XRD signal

212 contains all compositions along the axial direction of the NW shells.

213 For the barriers p- and n-AlGaInP we note that AlGaInP can be treated as a

214 combination of AlInP and GaInP. We found out by XRD measurements during

215 optimizing the composition of the $\mathrm{p}$ - and $\mathrm{n}$-AlGaInP layers that by adding $\chi_{\mathrm{TMAl}}$ while

216 keeping the $\chi_{\mathrm{TMG}}$ and $\chi_{\mathrm{TMI}}$ at the same value as for the $\mathrm{p}$-GaInP shell, the composition

217 shifts towards a more $\mathrm{Al} / \mathrm{Ga}$ rich $\mathrm{AlGaInP}$ layer as compared to In. Therefore we had to

218 use a lower $\chi_{\mathrm{TMG}}$ with respect to the previous p-GaInP layer to achieve lattice-matching.

219 If we assume that the $\mathrm{Ga}$ and $\mathrm{In}$ atoms from the respective precursor molecules are

220 similarly incorporated into AlGaInP as for the p-GaInP layer, then the addition of $\mathrm{Al}$ 
would by volume result in a higher growth rate. However, we cannot rule out that TMAl reduces the diffusion length of In species, not only dilutes them, and that some Ga atoms are replaced by $\mathrm{Al}$ atoms.

The intrinsic GaInP QW layer was grown with the same precursor molar fractions as for the p-GaInP layer since $\mathrm{Zn}$ did not affect the composition for shell growth, in agreement with thin-film growth. ${ }^{53,54}$

For the two n-type layers, two different dopants - Sn and S - were investigated independently of each other. The n-type dopant precursor molar fraction was 6 (5.4) times higher for $\chi_{\mathrm{TESn}}\left(\chi_{\mathrm{H} 2 \mathrm{~S}}\right)$ in the $\mathrm{n}$-GaInP layer than in the $\mathrm{n}$-AlGaInP layer since the outermost layer is intended to be electrically contacted. In case of $\mathrm{Sn}, \chi_{\mathrm{TMAl}}$ and $\chi_{\mathrm{TMG}}$ had to be reduced by $20 \%$ for the n-AlGaInP layer compared to the p-AlGaInP layer and $\chi_{\mathrm{TMG}}$ by $11 \%$ for the $\mathrm{n}-\mathrm{GaInP}$ layer compared to the $\mathrm{p}$ - and $\mathrm{i}-\mathrm{GaInP}$ layers, respectively, in order to achieve lattice-matching. For n-type doping with $\mathrm{S}$, we did not observe any large shift in composition upon doping.

Figure S1 shows the morphology of the n-GaInP outermost shells, doped with 236 Sn (Figure S1a) and S (Figure S1b), respectively, and intrinsic shells for comparison 237 (Figure S1c). The use of TESn leads to the formation of Sn-rich particles on the side 238 facets, similar to n-type shell doping by $\mathrm{Sn}$ of $\mathrm{GaP}^{51}$ and $\mathrm{InP}^{50}$ core-shell $\mathrm{NW}$ pn239 junctions. Also for S doping we see several irregularities on the morphology of the 240 surface but the effect is much weaker than for Sn. The NWs with the intrinsic two 241 outermost shells are up to $15 \%$ thicker than the n-type shells doped with Sn or S (not 242 visible in low magnification SEM images in Figure S1), probably because Sn forms a 243 surface accumulation layer ${ }^{55}$ and $\mathrm{S}$ acts as a surface passivator. ${ }^{56-58}$ Table $\mathrm{S} 1$ shows the 
244 molar fractions of the precursors during shell growth except for TMI, $\mathrm{PH}_{3}$ and DEZn

245 (for p-doping) since they were kept constant.

246 The compositional distribution across the entire NW cross-section,

247 perpendicular to the axial axis of the NWs, was investigated using STEM-EDX. The

248 different radially grown layers are visible in the HAADF STEM image in Figure 3a,

249 where the second highest $\chi_{\mathrm{TMAl}} /\left(\chi_{\mathrm{TMAl}}+\chi_{\mathrm{TMG}}\right)$ ratio out of five different runs (Table

250 S2) was used. The atomic resolution HAADF image (inset of Figure 3a) shows

251 relatively sharp hetero-interfaces with inter-diffusion of a few atomic layers, indicating

252 no or only small group III intermixing occurs at the hetero-interfaces. The calculated

253 material compositions from the STEM-EDX measurements for each segments across

254 the NW are shown in Figure 3d.

255 The segments in [110] direction (normal of the "m-plane") are relatively 256 homogeneous in composition with a slight In overweight in the i-GaInP QW layer, close

257 to the intended material compositions $\mathrm{Ga}_{0.47} \mathrm{In}_{0.53} \mathrm{P}$ and $\left(\mathrm{Al}_{\mathrm{x}} \mathrm{Ga}_{1-\mathrm{x}}\right)_{0.47} \mathrm{In}_{0.53} \mathrm{P}$. However, in

258 [112] direction (in the corners of the hexagon), there are segments with higher $\mathrm{Al}$

259 content in the p- and n-AlGaInP layers which can be seen as black stripes in Figure $3 \mathrm{a}$.

260 STEM-EDX elemental mapping of the NW composition confirmed Al rich

261 corners in AlGaInP and even Ga rich corners in i- and n-GaInP (Figure 3b). It showed

262 relative radial uniformity only for the $\mathrm{p}$-GaInP buffer layer. Starting from the p-

263 AlGaInP layer towards the outer shells, we observe areas in the six corners in [112]

264 direction with higher $\mathrm{Al}$ or $\mathrm{Ga}$ contents than in [110] direction. Al aggregates in the

265 corners of the quaternary shells and this phenomenon propagates through to the

266 respective outside lying neighboring shell all the way to the outermost n-GaInP shell.

267 The Ga rich corners in the $\mathrm{i}$ - and $\mathrm{n}$-GaInP shells are likely to be formed due to 
268 thermodynamic arguments. The atomic radius of $\mathrm{Ga}(130 \mathrm{pm})$ is far closer to the atomic

269 radius of $\mathrm{Al}(125 \mathrm{pm})$ than $\mathrm{In}(155 \mathrm{pm})$, therefore, for $\mathrm{Ga}$ atoms it might be more

270 favorable to deposit next to $\mathrm{Al}$ rich corners than next to the AlGaInP facets in [110]

271 direction. In other words, a layer tends to adopt the lattice constant of the neighboring

272 layer upon epitaxial processes. During XRD measurements for the separate layers, we

273 found a relatively broad signal for all shells except for the $\mathrm{p}$-GaInP shell. This could be

274 caused - besides the NW core material composition inhomogeneity in axial direction -

275 by the two different types of segments with different lattice constants in [110] and [112]

276 direction. Al rich vertices of a hexagon have also been observed in other core-shell NW

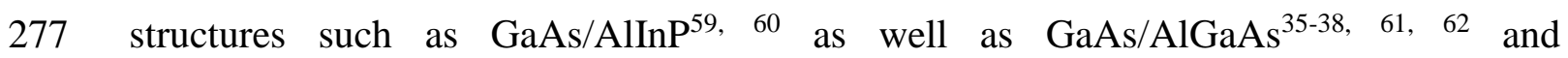

278 InAlN/GaN/InAlN ${ }^{40}$ MQWs.
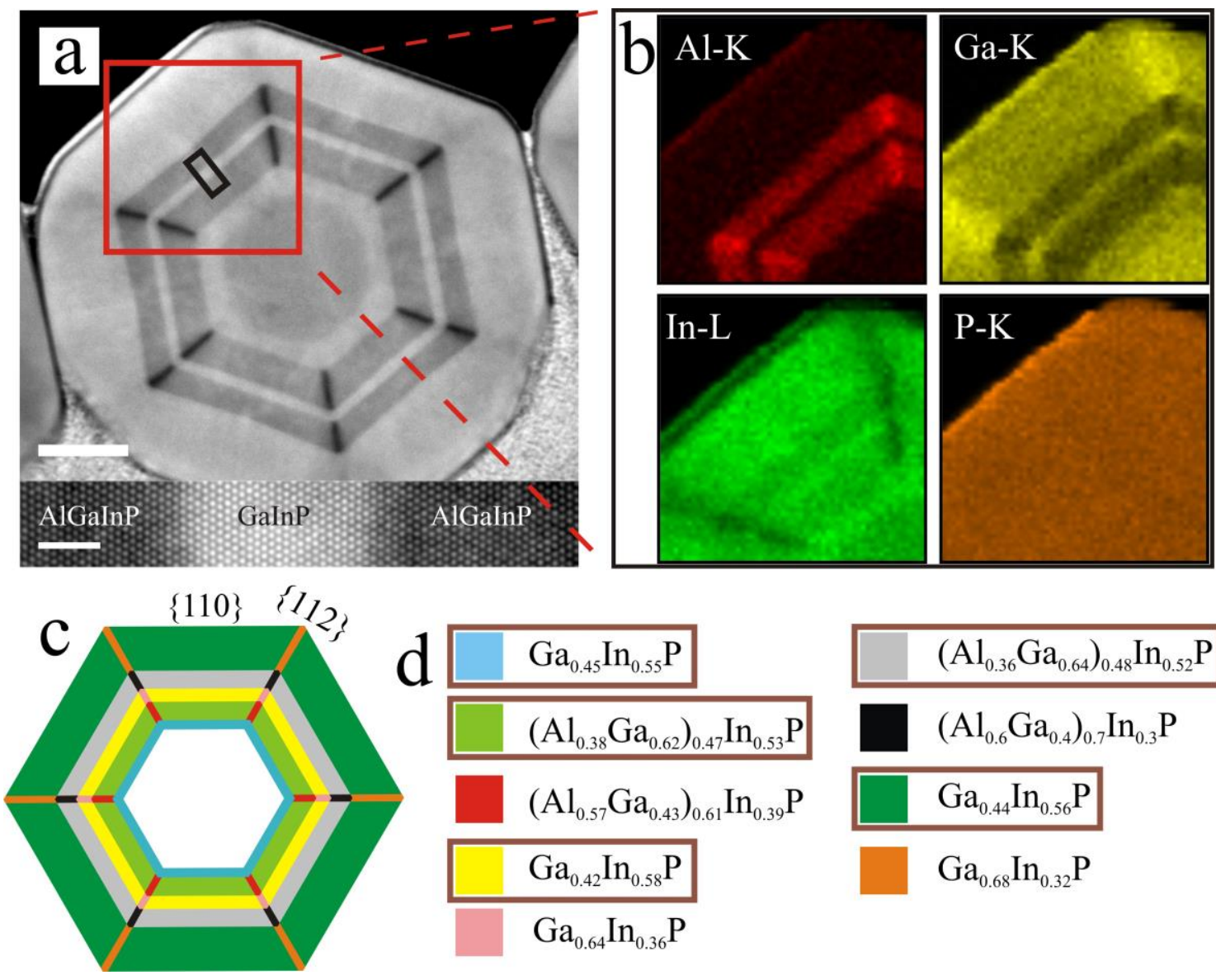

$$
\begin{aligned}
& \left(\mathrm{Al}_{0.36} \mathrm{Ga}_{0.64}\right)_{0.48} \mathrm{In}_{0.52} \mathrm{P} \\
& \left(\mathrm{Al}_{0.6} \mathrm{Ga}_{0.4}\right)_{0.7} \mathrm{In}_{0.3} \mathrm{P} \\
& \mathrm{Ga}_{0.44} \mathrm{In}_{0.56} \mathrm{P} \\
& \mathrm{Ga}_{0.68} \operatorname{In}_{0.32} \mathrm{P}
\end{aligned}
$$


280 Figure 3. Cross-section images perpendicular to the axial NW axis of radial 281 GaInP/AlGaInP/GaInP core-shell NWs with two AlGaInP layers as barriers where the

282 ratio $\chi_{\mathrm{TMAl}} /\left(\chi_{\mathrm{TMAl}}+\chi_{\mathrm{TMG}}\right)$ was 0.55 . (a) HAADF STEM image of a FIB-prepared 283 cross-sectional specimen of the whole core-shell NW (the scale bar is $50 \mathrm{~nm}$ ). The 284 cross-section was taken in the middle of the axial elongation of the NW. The inset 285 shows an atomic resolution STEM image of the GaInP/AlGaInP/GaInP interface from 286 the area in image a marked with a black rectangle (the scale bar in the inset is $2 \mathrm{~nm}$ ). (b) 287 STEM-EDX maps from the area marked with the red square in the HAADF image, 288 showing the $\mathrm{Al}, \mathrm{Ga}$, In and P distribution. (c) schematic cross-section image. The colors 289 indicate different compositions which are calculated in image d. (d) Material 290 composition of different regions of the NW, calculated from the EDX measurements. 291 All segments in [110] direction are nearly lattice-matched and marked with a brown 292 frame.

Sköld et al. ${ }^{59}$ analyzed $\mathrm{Al}$ rich corners in AlInP shells and argued that $\mathrm{Al}$ aggregates at the $\{112\}$ facets because In adatoms have a longer diffusion length than $\mathrm{Al}$ adatoms. In adatoms can therefore diffuse away from areas with high surface

297 energies more easily and we believe the same is true here for our quaternary AlGaInP 298 NW shells. Wagner et al. ${ }^{60}$ derived this phenomenon more in detail using surface 299 curvature where the adatoms diffuse toward the lower chemical potential. Phase 300 segregation has recently also been demonstrated in III-V-V ternary GaAsP core-shell 301 NWs with $\mathrm{P}$ enrichment in the corners of the hexagon. ${ }^{63}$ The authors argue that the 302 small $\{112\}$ facets have a curvature-induced high surface chemical potential, which 
303 makes it easier for the group V element arsenic (As) to diffuse away from the $\{112\}$

304 facets because of the longer diffusion length of its adatoms. ${ }^{63}$

305 The fact that the corners of the hexagon are Al/Ga richer as compared to In 306 means that the bandgap of the segments in [112] direction is higher. Thus, carriers will

307 preferably tend to diffuse to the lower-bandgap [110] direction, which means that the

308 lower-bandgap areas become recombination centers. The segments with smaller lattice 309 constants and higher bandgaps do not attract electrons, which would decrease the 310 recombination efficiency by strain-induced non-radiative recombination.

311 In order to demonstrate the potential of the GaInP/AlGaInP/GaInP core-shell

312 NWs for a radial NW LED, we evaluated their electro-optical properties. The $\chi_{\mathrm{TMAl}} /$

$313\left(\chi_{\mathrm{TMAl}}+\chi_{\mathrm{TMG}}\right)$ precursor ratio of 0.63 for the AlGaInP barriers (Figure S2) resulted in a

314 barrier height (conduction band offset) of about 118-194 meV (calculated after atomic

315 concentrations from STEM-EDX measurements and refs. ${ }^{64-66}$ where $\left(\mathrm{Al}_{\mathrm{x}} \mathrm{Ga}_{1-\mathrm{x}}\right)_{\mathrm{y}} \mathrm{In}_{1-\mathrm{y}} \mathrm{P}$

316 lattice-matched to GaAs was used $\left(\mathrm{y}=0.51\right.$ according to ref. $\left.{ }^{19}\right)$ ). The series of three

317 different growth times for the i-GaInP QW resulted in thicknesses of 5, 10 and $20 \mathrm{~nm}$

318 (estimated by the STEM image in Figure 3a where the QW thickness was about $5 \mathrm{~nm}$ 319 for a growth time of $15 \mathrm{~s})$.

320 For the $20 \mathrm{~nm}$ thick QWs the IL signal from $100 \times 100 \mu^{2}$ large devices is 321 relatively weak with a peak at $1.75-1.8 \mathrm{eV}$ (Figure 4a), which corresponds well to a 322 band-to-band electron-hole pair recombination with the bandgap of $\mathrm{Ga}_{0.42} \mathrm{In}_{0.58} \mathrm{P}$ at 1.79 $323 \mathrm{eV}^{19}$ where a bowing factor of $0.65 \mathrm{eV}$ for the $\Gamma$-band at $300 \mathrm{~K}$ was used ${ }^{19}$ or $1.75 \mathrm{eV} .^{25}$

324 For thinner QWs we observe a slight blue-shift of the IL peak which we attribute to 325 quantization. For $5 \mathrm{~nm}$ QW thickness the peak is broader than for $10 \mathrm{~nm}$, which can be 326 attributed to transitions from the quantized state and the ground state of the conduction 
band to the valence band. We find the highest IL intensity for a QW thickness of $10 \mathrm{~nm}$ (Figure 4a).

330 device with a $10 \mathrm{~nm}$ thick QW. This device has a threshold voltage of approximately 3

$331 \mathrm{~V}$, above which the NW LED starts to emit red light visible to the eye (Figure 4d). The

332 peak intensity increases with the current level (Figure 4c) and does not show any shift in energy. In reverse bias the device shows a current of $17 \mathrm{~mA}$ at $-3 \mathrm{~V}$ until breakdown occurs at about $-4 \mathrm{~V}$.
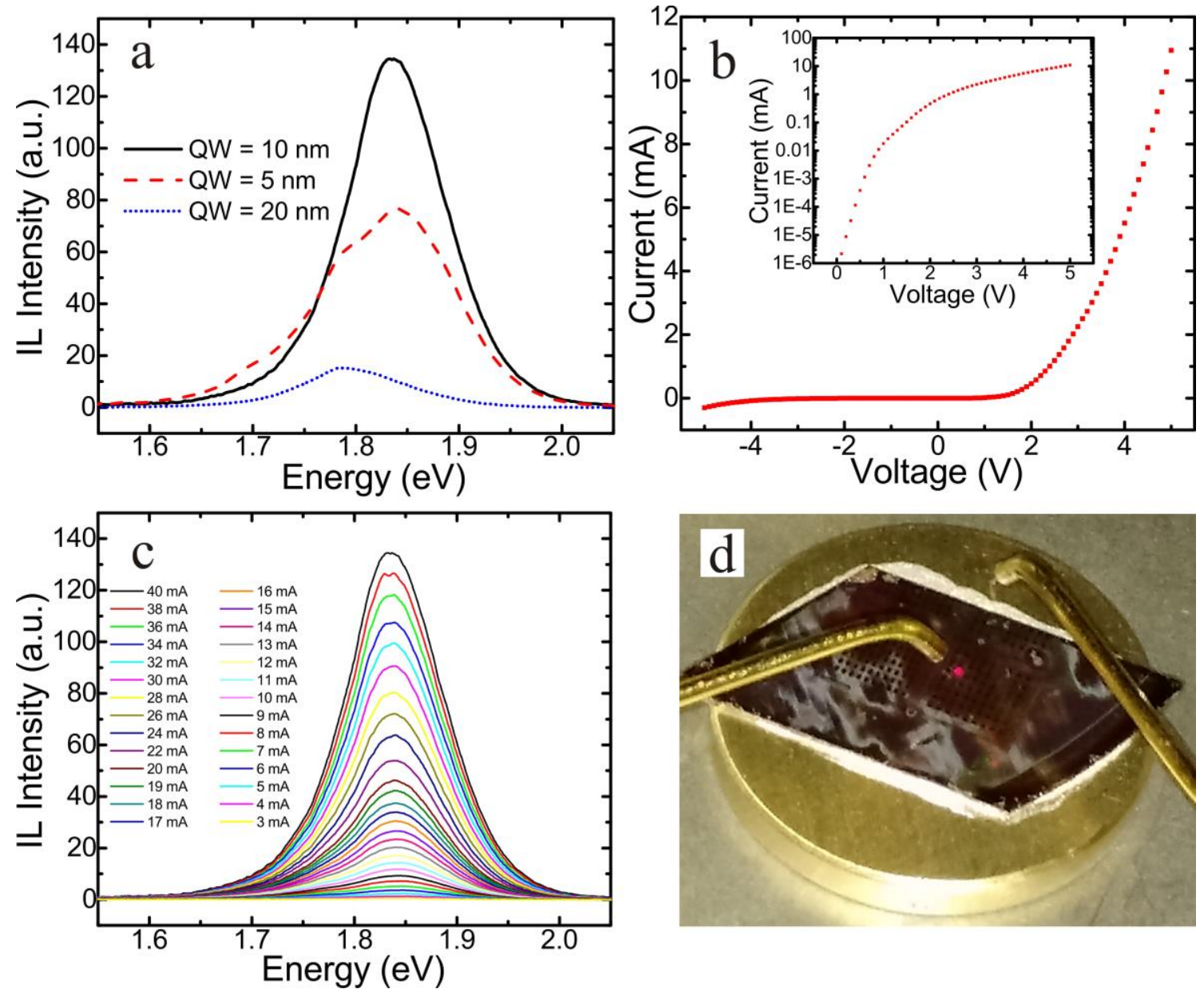

Figure 4. IL measurements on different radial GaInP/AlGaInP/GaInP core-shell NW

337 LED devices. In all 4 images, graphs from the same device with $10 \mathrm{~nm}$ QW thickness

338 are shown (image a shows IL spectra of two additional devices). (a) IL spectra of 3 
339 devices with different QW thicknesses at $40 \mathrm{~mA}$ as a function of the emission energy.

340 (b) IV characteristics. (c) IL spectra for a series of different currents as a function of the 341 energy. (d) photo of the red light emission of the sample in the probe station at a 342 forward bias of about $3 \mathrm{~V}$. 
In conclusion, we have presented an epitaxial growth scheme about a radial p-i-n

344 junction nanowire quantum well structure in the AlGaInP material system with GaInP

345 as the active layer. The n-type dopant Sn slightly changes the composition towards In

346 richer material. The material composition of each layer was determined by STEM-EDX.

347 We find $\mathrm{Al}$ rich corners in $\mathrm{AlGaInP}$ and relate that to a short diffusion length of $\mathrm{Al}$

348 adatoms. Finally we demonstrated the electro-optical properties of the NW light-

349 emitting diode devices. They illuminate with red color at a forward bias of around $3 \mathrm{~V}$. 


\section{ASSOCIATED CONTENT}

351

\section{Supporting Information}

352 Additional growth parameters. Morphology of the NW side facets for different n-type

353 dopants. Al content $x$ of the p-AlGaInP:Zn and n-AlGaInP:S barriers in $\left(\mathrm{Al}_{\mathrm{x}} \mathrm{Ga} \mathrm{1}_{-\mathrm{x}}\right) \operatorname{InP}$.

354 PL spectrum of a single NW with $10 \mathrm{~nm}$ QW thickness. This material is available free

355 of charge via the Internet at http://pubs.acs.org.

356

357 AUTHOR INFORMATION

358 Corresponding Author

$359 *$ magnus.borgstrom@ftf.lth.se

360

$361 \quad$ Present Address

$362 \perp$ Department of Materials Science and NanoEngineering, Rice University, 6100 Main

363 Street MS-325, Houston, TX 77005, United States

365 Author Contributions

366 The manuscript was written through contributions of all authors. All authors have given

367 approval to the final version of the manuscript.

368

369 Notes

370 The authors declare no competing financial interest.

371

372

ACKNOWLEDGMENT 
373 This work was performed within NanoLund and supported by the Swedish Research

374 Council (Vetenskapsrådet), the Swedish Foundation for Strategic Research (SSF), by 375 the Knut and Alice Wallenberg Foundation, and by the EU program NWs4Light under 376 grant 280773. 


\section{REFERENCES}

1. Wallentin, J.; Anttu, N.; Asoli, D.; Huffman, M.; Åberg, I.; Magnusson, M. H.; Siefer, G.; Fuss-Kailuweit, P.; Dimroth, F.; Witzigmann, B.; Xu, H. Q.; Samuelson, L.; Deppert, K.; Borgström, M. T. Science 2013, 339, (6123), 1057-1060.

2. Tomioka, K.; Yoshimura, M.; Fukui, T. Nature 2012, 488, (7410), 189-192.

3. Gudiksen, M. S.; Lauhon, L. J.; Wang, J.; Smith, D. C.; Lieber, C. M. Nature 2002, 415, (6872), 617-620.

4. Wirth, R.; Karnutsch, C.; Kugler, S.; Streubel, K. Ieee Photonic Tech L 2001, 13, (5), 421-423.

5. Sigai, A. G.; Nuese, C. J.; Enstrom, R. E.; Zamerowsi, T. J Electrochem Soc 1973, 120, (7), 947-955.

6. Nuese, C. J.; Sigai, A. G.; Abrahams, M. S.; Gannon, J. J. J Electrochem Soc 1973, 120, (7), 956-965.

7. Nuese, C. J.; Sigai, A. G.; Gannon, J. J.; Zamerowsi, T. J Electron Mater 1974, $3,(1), 51-78$.

8. $\quad$ Stinson, L. J.; Yu, J. G.; Lester, S. D.; Peanasky, M. J.; Park, K. Applied Physics Letters 1991, 58, (18), 2012-2014.

9. $\quad$ Kondo, S.; Matsumoto, S.; Nagai, H. Applied Physics Letters 1988, 53, (4), 279281.

10. Ermakov, O. N.; Garba, L. S.; Golovanov, Y. A.; Sushkov, V. P.; Chukichev, M. V. Ieee T Electron Dev 1979, 26, (8), 1190-1193.

11. Chang, S. J.; Chang, C. S. Japanese Journal of Applied Physics Part 2 1998, 37, (6A), L653-L655.

12. Chang, S. J.; Chang, C. S. Ieee Photonic Tech L 1998, 10, (6), 772-774.

13. Greger, E.; Gulden, K. H.; Riel, P.; Schweizer, H. P.; Moser, M.; Schmiedel, G.; Kiesel, P.; Dohler, G. H. Applied Physics Letters 1996, 68, (17), 2383-2385.

14. Marmalyuk, A. A.; Gorlachuk, P. V.; Ryaboshtan, Y. L.; Brudnyi, V. N.; Prudaev, I. A.; Romanov, I. S.; Lelekov, M. A. Russ Phys J+ 2013, 56, (8), 894-897.

15. McGill, L.; Wu, J. W.; Fitzgerald, E. A. Journal of Applied Physics 2004, 95, (12), 7561-7566.

16. Dawson, M. D.; Duggan, G. Applied Physics Letters 1994, 64, (7), 892-894.

17. Lee, C. Y.; Wu, M. C.; Lin, W. Journal of Crystal Growth 1999, 200, (3-4), 382-390.

18. Rooman, C.; Windisch, R.; D'Hondt, M.; Dutta, B.; Modak, P.; Mijlemans, P.; Borghs, G.; Vounckx, R.; Moerman, I.; Kuijk, M.; Heremans, P. Electron Lett 2001, 37, (13), 852-853.

19. Vurgaftman, I.; Meyer, J. R.; Ram-Mohan, L. R. Journal of Applied Physics 2001, 89, (11), 5815-5875.

20. Physical Properties of Semiconductors, Ioffe Institute, Sankt Petersburg, Russia; http://www.ioffe.ru/SVA/NSM/Semicond/.

21. Kish, F. A.; Steranka, F. M.; Defevere, D. C.; Vanderwater, D. A.; Park, K. G.; Kuo, C. P.; Osentowski, T. D.; Peanasky, M. J.; Yu, J. G.; Fletcher, R. M.; Steigerwald, D. A.; Craford, M. G.; Robbins, V. M. Applied Physics Letters 1994, 64, (21), 28392841.

22. Höfler, G. E.; Vanderwater, D. A.; DeFevere, D. C.; Kish, F. A.; Camras, M. D.; Steranka, F. M.; Tan, I. H. Applied Physics Letters 1996, 69, (6), 803-805. 
23. Gardner, N. F.; Chui, H. C.; Chen, E. I.; Krames, M. R.; Huang, J. W.; Kish, F. A.; Stockman, S. A.; Kocot, C. P.; Tan, T. S.; Moll, N. Applied Physics Letters 1999, 74, (15), 2230-2232.

24. Dakin, J.; Brown, R. G. W., Handbook of Optoelectronics - Volume I. Taylor \& Francis: New York, 2006.

25. Schubert, E. F., Light-emitting diodes. 2nd ed.; Cambridge University Press: Cambridge; New York, 2006.

26. Mårtensson, T.; Svensson, C. P. T.; Wacaser, B. A.; Larsson, M. W.; Seifert, W.; Deppert, K.; Gustafsson, A.; Wallenberg, L. R.; Samuelson, L. Nano Letters 2004, 4, (10), 1987-1990.

27. Roest, A. L.; Verheijen, M. A.; Wunnicke, O.; Serafin, S.; Wondergem, H.; Bakkers, E. P. A. M. Nanotechnology 2006, 17, (11), S271-S275.

28. Qian, F.; Li, Y.; Gradečak, S.; Wang, D. L.; Barrelet, C. J.; Lieber, C. M. Nano Letters 2004, 4, (10), 1975-1979.

29. Qian, F.; Gradečak, S.; Li, Y.; Wen, C. Y.; Lieber, C. M. Nano Letters 2005, 5, (11), 2287-2291.

30. Svensson, C. P. T.; Mårtensson, T.; Tragårdh, J.; Larsson, C.; Rask, M.; Hessman, D.; Samuelson, L.; Ohlsson, J. Nanotechnology 2008, 19, (30), 305201.

31. Kawaguchi, K.; Sudo, H.; Matsuda, M.; Takemoto, K.; Yamamoto, T.; Arakawa, Y. Applied Physics Letters 2015, 106, (1), 012107.

32. Kawaguchi, K.; Sudo, H.; Matsuda, M.; Ekawa, M.; Yamamoto, T.; Arakawa, Y. Japanese Journal of Applied Physics 2015, 54, (4S), 04DN02.

33. Hiruma, K.; Tomioka, K.; Mohan, P.; Yang, L.; Noborisaka, J.; Hua, B.; Hayashida, A.; Fujisawa, S.; Hara, S.; Motohisa, J.; Fukui, T. Journal of Nanotechnology 2012, 2012, 29.

34. Mohan, P.; Motohisa, J.; Fukui, T. Applied Physics Letters 2006, 88, (13), 133105 .

35. Mancini, L.; Fontana, Y.; Conesa-Boj, S.; Blum, I.; Vurpillot, F.; Francaviglia, L.; Russo-Averchi, E.; Heiss, M.; Arbiol, J.; Fontcuberta i Morral, A.; Rigutti, L. Applied Physics Letters 2014, 105, (24), 243106.

36. Heiss, M.; Fontana, Y.; Gustafsson, A.; Wust, G.; Magen, C.; O'Regan, D. D.; Luo, J. W.; Ketterer, B.; Conesa-Boj, S.; Kuhlmann, A. V.; Houel, J.; Russo-Averchi, E.; Morante, J. R.; Cantoni, M.; Marzari, N.; Arbiol, J.; Zunger, A.; Warburton, R. J.; Morral, A. F. I. Nat Mater 2013, 12, (5), 439-444.

37. Fickenscher, M.; Shi, T.; Jackson, H. E.; Smith, L. M.; Yarrison-Rice, J. M.; Zheng, C. L.; Miller, P.; Etheridge, J.; Wong, B. M.; Gao, Q.; Deshpande, S.; Tan, H. H.; Jagadish, C. Nano Letters 2013, 13, (3), 1016-1022.

38. Zheng, C. L.; Wong-Leung, J.; Gao, Q.; Tan, H. H.; Jagadish, C.; Etheridge, J. Nano Letters 2013, 13, (8), 3742-3748.

39. Armitage, R.; Tsubaki, K. Nanotechnology 2010, 21, (19), 195202.

40. Durand, C.; Bougerol, C.; Carlin, J. F.; Rossbach, G.; Godel, F.; Eymery, J.; Jouneau, P. H.; Mukhtarova, A.; Butté, R.; Grandjean, N. Acs Photonics 2014, 1, (1), $38-46$.

41. Qian, F.; Brewster, M.; Lim, S. K.; Ling, Y. C.; Greene, C.; Laboutin, O.; Johnson, J. W.; Gradecak, S.; Cao, Y.; Li, Y. Nano Letters 2012, 12, (6), 3344-3350. 42. Carlberg, P.; Graczyk, M.; Sarwe, E. L.; Maximov, I.; Beck, M.; Montelius, L. Microelectron Eng 2003, 67-68, 203-207. 
43. Eriksson, T.; Yamada, S.; Krishnan, P. V.; Ramasamy, S.; Heidari, B. Microelectron Eng 2011, 88, (3), 293-299.

44. Berg, A.; Lenrick, F.; Vainorius, N.; Beech, J. P.; Wallenberg, L. R.; Borgström, M. T. Nanotechnology 2015, 26, (43), 435601.

45. Borgström, M. T.; Wallentin, J.; Trägårdh, J.; Ramvall, P.; Ek, M.; Wallenberg, L.; Samuelson, L.; Deppert, K. Nano Research 2010, 3, (4), 264-270.

46. Berg, A.; Lehmann, S.; Vainorius, N.; Gustafsson, A.; Pistol, M.-E.; Wallenberg, L. R.; Samuelson, L.; Borgström, M. T. Journal of Crystal Growth 2014, $386,(0), 47-51$.

47. Jacobsson, D.; Persson, J. M.; Kriegner, D.; Etzelstorfer, T.; Wallentin, J.; Wagner, J. B.; Stangl, J.; Samuelson, L.; Deppert, K.; Borgström, M. T. Nanotechnology 2012, 23, (24), 245601.

48. Assali, S.; Zardo, I.; Plissard, S.; Kriegner, D.; Verheijen, M. A.; Bauer, G.; Meijerink, A.; Belabbes, A.; Bechstedt, F.; Haverkort, J. E. M.; Bakkers, E. P. A. M. Nano Letters 2013, 13, (4), 1559-1563.

49. Green, T. A. Gold Bull 2014, 47, (3), 205-216.

50. Heurlin, M.; Hultin, O.; Storm, K.; Lindgren, D.; Borgström, M. T.; Samuelson, L. Nano Letters 2014, 14, (2), 749-753.

51. Yazdi, S.; Berg, A.; Borgström, M. T.; Kasama, T.; Beleggia, M.; Samuelson, L.; Wagner, J. B. Small 2015, 11, (22), 2687-2695.

52. Nowzari, A.; Heurlin, M.; Jain, V.; Storm, K.; Hosseinnia, A.; Anttu, N.; Borgström, M. T.; Pettersson, H.; Samuelson, L. Nano Letters 2015, 15, (3), 1809-1814. 53. Lee, S. H.; Fetzer, C. M.; Stringfellow, G. B.; Choi, C. J.; Seong, T. Y. Journal of Applied Physics 1999, 86, (4), 1982-1987.

54. Wu, M. C.; Su, Y. K.; Chang, C. Y.; Cheng, K. Y. Journal of Applied Physics 1985, 58, (11), 4317-4321.

55. Clawson, A. R.; Hanson, C. M. J Electron Mater 1991, 20, (5), 365-372.

56. Hou, X. Y.; Cai, W. Z.; He, Z. Q.; Hao, P. H.; Li, Z. S.; Ding, X. M.; Wang, X. Applied Physics Letters 1992, 60, (18), 2252-2254.

57. Ohno, T. Phys Rev B 1991, 44, (12), 6306-6311.

58. Tian, S. S.; Wei, Z. P.; Li, Y. F.; Zhao, H. F.; Fang, X.; Tang, J. L.; Fang, D.; Sun, L. J.; Liu, G. J.; Yao, B.; Ma, X. H. Mat Sci Semicon Proc 2014, 17, 33-37.

59. Sköld, N.; Wagner, J. B.; Karlsson, G.; Hernan, T.; Seifert, W.; Pistol, M. E.; Samuelson, L. Nano Letters 2006, 6, (12), 2743-2747.

60. Wagner, J. B.; Sköld, N.; Wallenberg, L. R.; Samuelson, L. Journal of Crystal Growth 2010, 312, (10), 1755-1760.

61. Rudolph, D.; Funk, S.; Doblinger, M.; Morkötter, S.; Hertenberger, S.; Schweickert, L.; Becker, J.; Matich, S.; Bichler, M.; Spirkoska, D.; Zardo, I.; Finley, J. J.; Abstreiter, G.; Koblmüler, G. Nano Letters 2013, 13, (4), 1522-1527.

62. Jiang, N.; Gao, Q.; Parkinson, P.; Wong-Leung, J.; Mokkapati, S.; Breuer, S.; Tan, H. H.; Zheng, C. L.; Etheridge, J.; Jagadish, C. Nano Letters 2013, 13, (11), 51355140.

63. Zhang, Y.; Sanchez, A. M.; Wu, J.; Aagesen, M.; Holm, J. V.; Beanland, R.; Ward, T.; Liu, H. Nano Letters 2015, 15, (5), 3128-3133.

64. Meney, A. T.; Prins, A. D.; Phillips, A. F.; Sly, J. L.; Oreilly, E. P.; Dunstan, D. J.; Adams, A. R.; Valster, A. Ieee J Sel Top Quant 1995, 1, (2), 697-706.

65. Yow, H. K.; Houston, P. A.; Hopkinson, M. Applied Physics Letters 1995, 66, (21), 2852-2854. 
519 520 521 522

523 524

525 66. Zhang, X. H.; Chua, S. J.; Fan, W. J. Applied Physics Letters 1998, 73, (8), 1098-1100.

\section{Table of Contents Graphic}

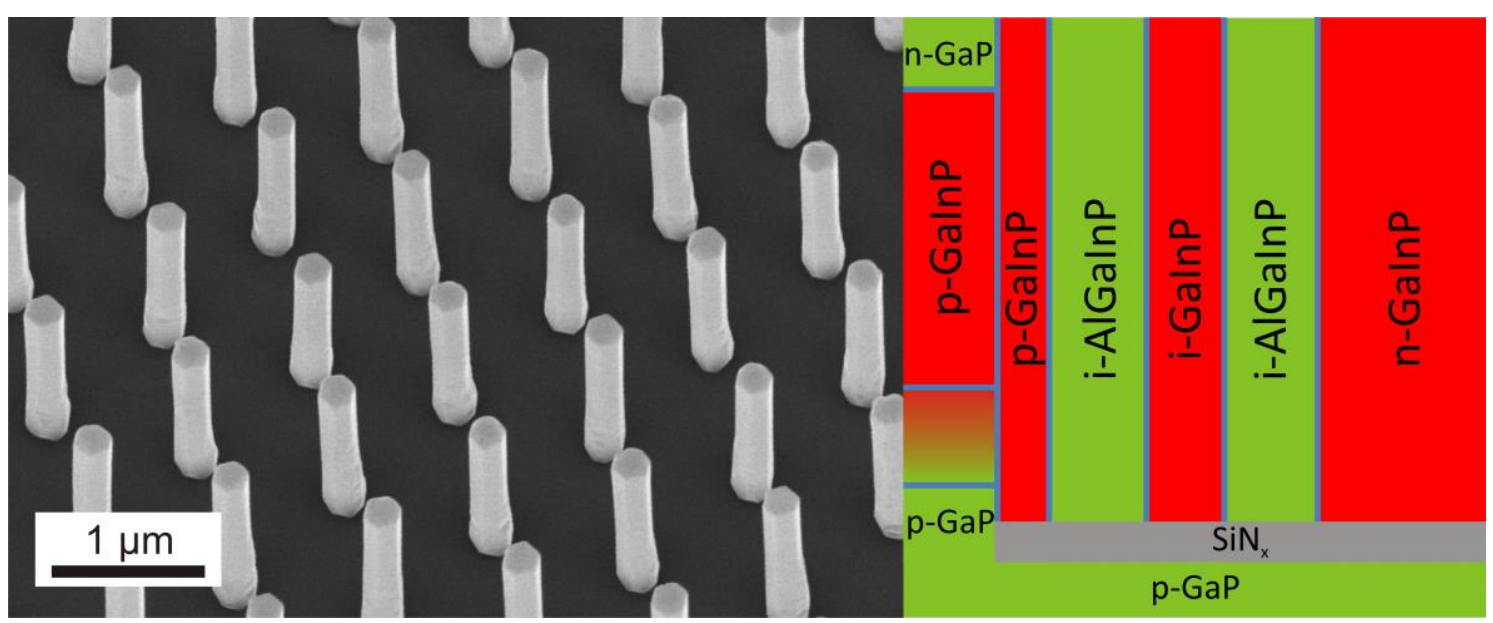

